\title{
AMPLIAÇÃO DA ASSISTÊNCIA JURÍDICA GRATUITA PRESTADA PELA DEFENSORIA PÚBLICA DA UNIÁO EM PARCERIA COM A DIOCESE DE VALENÇA/ RJ: RELATO DE UMA EXPERIÊNCIA DA JUSTIÇA ITINERANTE
}

\author{
EXPANSION OF FREE LEGAL ASSISTANCE PROVIDED BY THE PUBLIC DEFENDER \\ OF THE UNION IN PARTNERSHIP WITH THE DIOCESE OF VALENÇA / RJ: \\ REPORT OF AN EXPERIENCE OF ITINERANT JUSTICE
}

José Roberto Fani Tambasco

Doutor em Ciências Juridicas e Sociais (UMSA -AR) Defensor Público Federal. Coordenador do projeto itinerante da $1{ }^{a}$ Categoria da DPU/RJ jose.tambasco@dpu.def.br

José Antônio da Silva

Doutorando em Direito Canônico pela Pontifícia Universidade Católica de Buenos Aires (UCA-AR) Mestre em Direito Canônico, Bacharel em Teologia, Licenciatura em Filosofia e Sociologia

Pároco da Paróquia Nossa Senhora da Conceição, Vassouras/RJ. Vigário Geral da Diocese de Valença/RJ

janthonius@uol.com.br

Gabriel Silva Rezende

Doutorando em Ciências Sociais (Ciência Politica) na Pontifícia Universidade Católica do Rio de Janeiro, Mestre em Sociologia Politica pelo Instituto Universitário de Pesquisas do Rio de Janeiro e Bacharel em Relaçóes Internacionais pela Universidade Candido Mendes (RJ)

Pesquisador do Núcleo de Estudos sobre Federalismo, Política e Desenvolvimento da PUC-Rio/CNPQ gabrielsrezende10@gmail.com

André da Silva Ordacgy Mestre em Estado, Direito e Justiça pela UNESA Pós-Graduado em Direito Civil pela UNESA Chefe da Primeira Categoria da Defensoria Pública da União no RJ Defensor Público Federal. andre.ordacgy@dpu.def.br

Alessandra Fonseca de Carvalho Mestre em Ciências Jurídico-Politicas no Perfil de Direitos Fundamentais pela Universidade de Lisboa Defensora Pública Federal. alessandra.carvalho@dpu.def.br

Maria Cecília Lessa da Rocha

Doutoranda em Direito Mestre em Ciências Jurídicas pela Pontifícia Universidade Católica do Rio de Janeiro Defensora Pública Federal maria.rocha@dpu.def.br 


\section{INTRODUÇÁO}

A Constituição Federal do Brasil, promulgada em 05 de outubro de 1988 e reconhecida como "Constituição Cidadâ", preocupou-se em conferir aos cidadãos a garantia constitucional de assistência jurídica integral e gratuita, em completo atendimento aos princípios da dignidade humana, igualdade e devido processo legal. Nesse cenário, o acesso à justiça se destaca como o direito garantidor de outros direitos, como arcabouço protetivo dos direitos fundamentais.

A Defensoria Pública da União - DPU, na forma do art. 134 da Constituição Federal de 1988, é instituição permanente, essencial à função jurisdicional do Estado, incumbindolhe, como expressão e instrumento do regime democrático, fundamentalmente, a promoçấo dos direitos humanos e a orientação jurídica aos necessitados diante das demandas administrativas e judiciais inerentes às justiças federal, trabalhista, eleitoral e militar ${ }^{1}$.

A Defensoria Pública da Uniáo foi implantada em caráter emergencial e provisório através da Lei $\mathrm{n}^{\circ} 9.020$, de 30 de março de 1995, assim permanecendo por diversos anos. Enquanto as Defensorias Públicas Estaduais obtiveram do poder constituinte derivado autonomia funcional e administrativa e a iniciativa de sua proposta orçamentária por meio da Emenda Constitucional no 45, de 30 de dezembro de 2004, a DPU apenas alcançou o mesmo status com o advento da Emenda Constitucional no 74, de 06 de agosto de 2013, o que, em termos práticos, representou significativo atraso em seu processo de estruturação e consolidação.

Atualmente, em que pese a determinaçáo constitucional contida no $\$ 1^{\circ}$ do art. 98 dos Atos das Disposiçōes Constitucionais Transitórias, inserido pela Emenda Constitucional no 80 , de 04 de junho de 2014, que estabelece que "no prazo de 8 (oito) anos, a União, os Estados e o Distrito Federal deverão contar com defensores públicos em todas as unidades jurisdicionais", o acesso ao serviço prestado por esta instituição ainda não foi efetivado na maioria das subseçôes da Justiça Federal de todos os estados do país.

Nesse contexto, implementou-se institucionalmente uma solução de atendimento provisório em caráter itinerante, que, utilizando-se dos recursos existentes, procura minimizar a ausência do serviço de assistência jurídica gratuita nos municípios que não possuem instalados na sua subseção federal uma sede da DPU.

No Estado do Rio de Janeiro (figura 1), a DPU possui sede operacional somente nas cidades do Rio de Janeiro, Niterói (que abrange também as subseçóes de São Gonçalo e Itaboraí), São João de Meriti (que abrange também as subseçôes de Duque de Caxias e Nova Iguaçu) e Volta Redonda. Razóes que levaram aos defensores atuantes na área recursal, denominada primeira categoria, da DPU na cidade do Rio de Janeiro a participarem dos projetos itinerantes de caráter estadual implementados a partir do ano de 2017.

\footnotetext{
1 CRFB/88 -Art. 134. A Defensoria Pública é instituição permanente, essencial à função jurisdicional do Estado, incumbindo-lhe, como expressão e instrumento do regime democrático, fundamentalmente, a orientação jurídica, a promoção dos direitos humanos e a defesa, em todos os graus, judicial e extrajudicial, dos direitos individuais e coletivos, de forma integral e gratuita, aos necessitados, na forma do inciso LXXIV do art. $5^{\circ}$ desta Constituição Federal.
} 


\section{Figura 1: Divisáo Regional e Municipal do Estado do Rio de Janeiro}

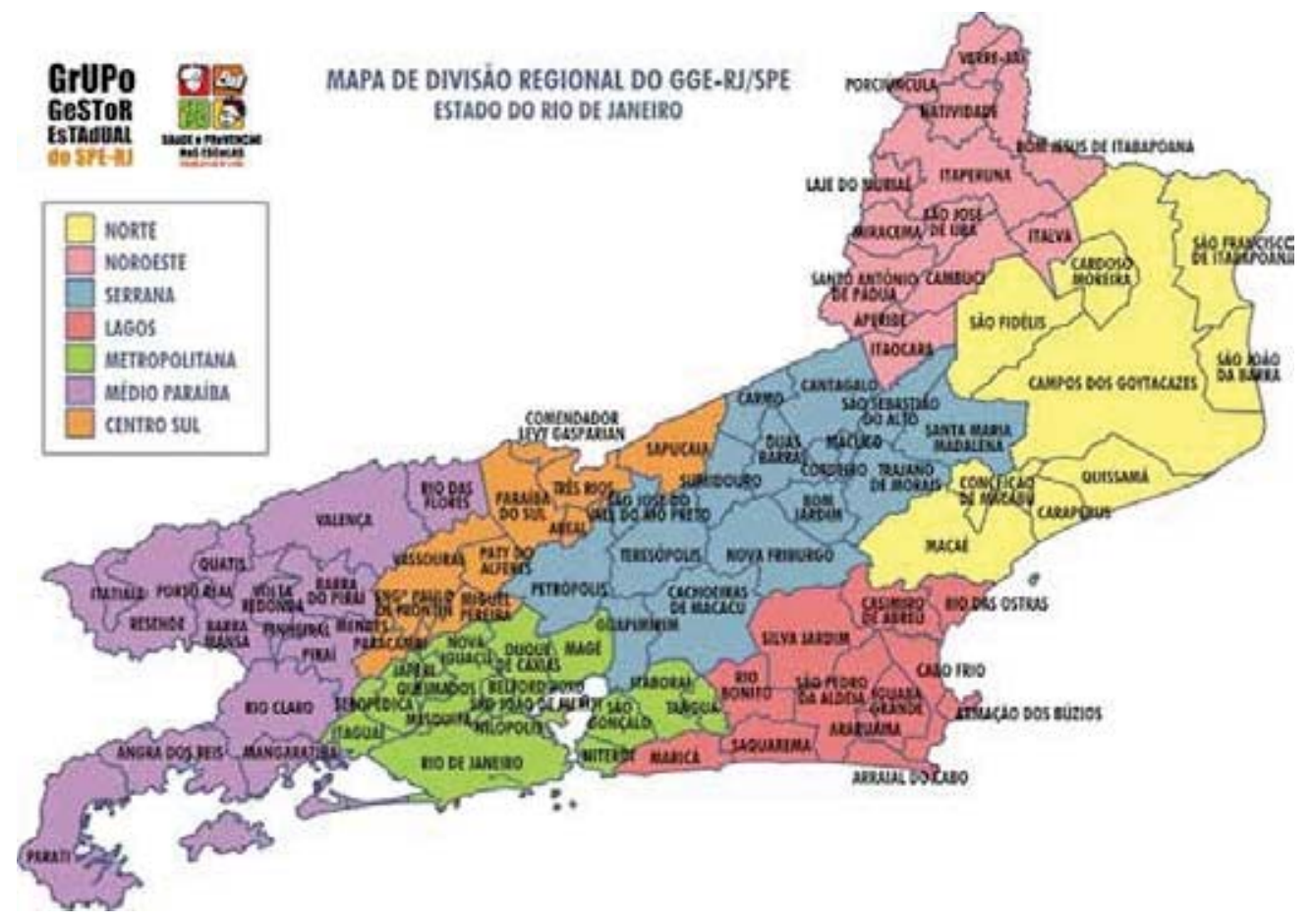

Em face das dificuldades operacionais encontradas para cumprir o seu papel constitucional e para alcançar efetivamente a população sem acesso à assistência jurídica gratuita nas localidades atendidas pelos núcleos da DPU, partimos do princípio de que é de suma importância a realização de parcerias com entidades públicas e privadas que possam colaborar eficazmente com a difusão do acesso ao conhecimento jurídico e a devida assistência judiciária gratuita.

A experiência obtida na realização destes eventos a nível estadual demonstrou que o elemento primordial para a realização destas parcerias, além da busca pela otimização da alocaçáa dos recursos escassos disponíveis, é a garantia da continuidade da prestação do serviço através da formação de uma linha direta entre os assistidos e a DPU.

Esta fase que podemos denominar pós-atendimento, visa possibilitar que os documentos não apresentados no momento do atendimento itinerante sejam repassados à DPU, assim como facilitar a troca de informaçóes entre os assistidos e os defensores para que sejam esclarecidos pontos necessários à obtenção das orientações requeridas e também para a propositura das açóes judiciais que se fizerem necessárias.

Consequentemente, diante da necessidade da continuidade do serviço prestado e a busca pelo seu aprimoramento, a DPU apresentou proposta de parceria para realização de um projeto itinerante à Diocese de Valença, RJ, cuja área de atuaçáo territorial é de 3.963,9 $\mathrm{km}^{2}$, e cuja população residente é de 364.348 habitantes (IBGE 2014), distribuída pelos 
municípios de Comendador Levy Gasparian, Miguel Pereira, Paraíba do Sul, Paty do Alferes, Rio das Flores, Sapucaia, Três Rios, Valença e Vassouras, os quais possuem competência jurisdicional dividida entre as subseçóes federais de Barra do Piraí (amarelo), Tres Rios (verde) e Nova Iguaçu (vermelho), conforme a figura 2.

\section{Figura 2: Território Eclesiástico da Diocese de Valença e as competências jurisdicionais}

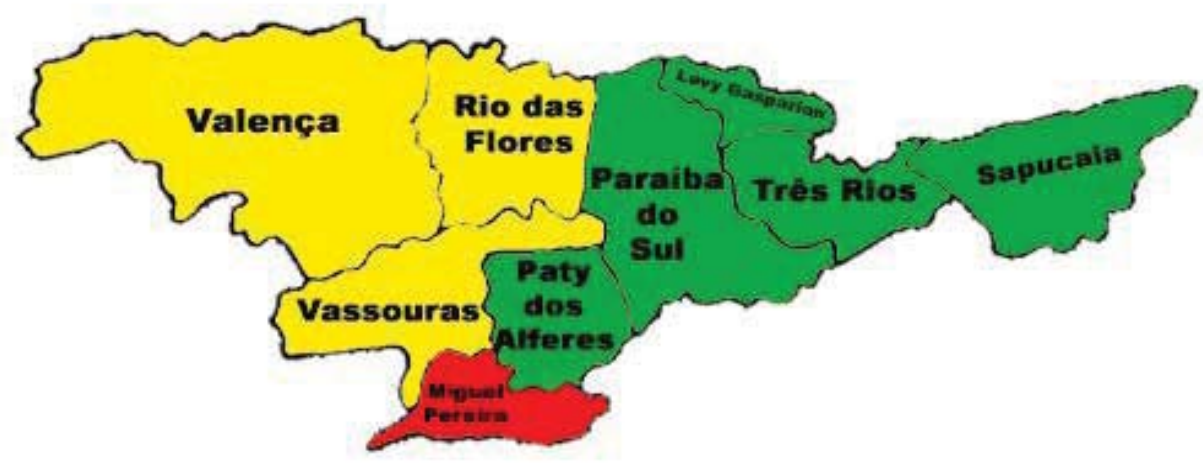

Este projeto foi efetivado em todos os municípios supra elencados durante os meses de junho a setembro do ano de 2019, com participação dos Defensores Públicos Federais, representante da Diocese, Párocos locais, Comunidades Eclesiais e Secretarias Municipais de Assistência Social.

Importante frisar que o fato de a República Federativa do Brasil ser um Estado laico (artigo 5, VI e 19, I da CRFB) não é óbice para que se possa manter relaçóes com entidades e organismos religiosos, na forma do Decreto $n^{\circ} 7.107$, de 11 de fevereiro de 2010, que promulgou o acordo entre o governo brasileiro e a Santa Sé, definindo o Estatuto Jurídico da Igreja Católica no Brasil e reconhecendo a personalidade jurídica da Igreja Católica.

A aproximação dos interesses tutelados pela Defensoria Pública e a matéria canônica não apresenta nenhum imperativo novo, visto que a igreja foi uma das instituiçóes que serviram de estímulo para o incremento do serviço de assistência jurídica dos necessitados ao longo da história.

Note-se ainda que a Igreja Católica funcionou nessa experiência como elo da DPU com a comunidade local, sendo certo que o atendimento foi feito a todos que procuraram a instituição durante os dias de itinerância, sem discriminação de credo, ou seja, em momento algum se observou a crença religiosa como critério para a prestação do serviço público.

Por fim, diante dos resultados positivos alcançados na elaboração deste projeto itinerante, em todas as suas fases de implementação, entendeu-se de extrema relevância traze-lo ao conhecimento do público em geral, a fim de demonstrar a viabilidade da construção de um modelo a ser implementado a nível nacional com vistas a minimizar a carência de assistência jurídica à grande massa da população desassistida na garantia do acesso aos seus direitos fundamentais, especialmente quando se trata de acesso à Justiça Federal. 


\section{ACESSO À JUSTIÇA: A DEFENSORIA COMO UM DOS CAMINHOS VIÁVEIS}

$\mathrm{O}$ acesso à justiça encontra enormes obstáculos em sociedades em que os direitos fundamentais não foram, na prática, estabelecidos, como no caso do Brasil, diante do processo histórico e social de desigualdade, além das assimetrias entre as unidades federativas (REIS, 2005). A deficiência na prestação de serviços jurídicos pode ser compreendida como mais um indicador de desigualdade no Brasil. Estando longe de garantir o direito de acesso à justiça para as populaçôes de baixa renda.

Nesse sentido, ao apreendermos essa estrutura e as suas dificuldades relacionadas ao acesso à justiça, Capelletti e Garth (1988) analisam que os principais entraves à justiça seriam: os altos custos inerentes ao sistema judicial; a dificuldade dos cidadáos em reconhecer que possuem determinados direitos e em que momento os mesmos acabam violados, além da falta de disposição psicológica para buscar sua reparação através de uma demanda judicial.

É crível ressaltarmos, como assevera Oliveira (2018), que o acesso à justiça é apenas um de diversos direitos essenciais para o exercício da plena cidadania a serem protegidos pelo Estado, como dever deste, de acordo com a leitura do Pacto de San José da Costa Rica, em seu Art. $8^{\circ}$, sobre as Garantias Judiciais e também estabelecido pela Constituição Federal de 1988 (CIDH, 1969; CRFB, 1988). Em que se destaca a Defensoria Pública como instituição ativa e altiva para resguardar esses direitos essenciais dos cidadãos.

Nesse sentido, qualificar a Defensoria Pública como expressão e instrumento do regime democrático é reconhecer que sua atuaçáo é representativa na busca por um acesso à justiça efetivo, bem como democrático quanto meio adequado para sua sedimentaçáo (ASSIS, 2019). Salientamos, assim, que o artigo 185 do CPC/2015 reproduz parcialmente o artigo 134 da CRFB/1988, destacando que o papel da Defensoria Pública enquanto instituição basilar de orientação jurídica, de promoção dos direitos humanos é a defesa dos direitos fundamentais individuais e coletivos dos necessitados.

Assis (2019), compreende que o conceito de orientaçáo jurídica deve ser entendido como a atuação judicial e extrajudicial relacionada náo apenas à consultoria e postulação, mas também à educação em direitos, conciliação, mediação, dentre outras funções. Ao mesmo tempo que se deve entender que o termo "necessitado" se relaciona com o hipossuficiente de forma geral, seja de viés econômico, jurídico ou organizacional.

Por certo que o Código de Processo Civil de 2015, supracitado, não conseguirá resolver todas as dificuldades e logística que envolvem a atividade da Defensoria dada extensão territorial brasileira. Não obstante, o espaço dado à instituição, respeitando seu regime jurídico constitucional e sua legislação de regência, estimula a participação e a busca de instituiçôes da sociedade civil através de parcerias. No intuito da realização integral das funçôes da Defensoria Pública, que consiste não apenas em atender as demandas, mas chegar aos indivíduos e coletividades mais vulneráveis, para a efetivação e concretização dos direitos fundamentais.

Nesse sentido, podemos observar, como analisam Oliveira (2018) e Souza (2006), que a DPU itinerante, é um dos caminhos para alcançar os indivíduos e grupos hipossuficien- 
tes, e o produto - mutatis mutandis - do entendimento de políticas públicas como um campo de conhecimento que busca analisar as açóes do governo (conteúdo), como elas se dão (processo) e, a partir desse momento, motivar a ação governamental com novas propostas ou observaçôes importantes para o aprimoramento do todo. Logo, a DPU itinerante enquanto ação do governo de promoção do acesso à justiça tem sido construída e implementada, levando em consideração os atores hipossuficientes. Dessa forma, partimos da premissa de que Justiça Itinerante é uma Política Pública que busca a democratização do acesso à justiça. Isso porque, conforme ressalta Oliveira (2018), as açóes itinerantes vão além das estruturas sedes, parte do sistema judiciário e atingem populaçóes sem acesso a esses serviços que, porém, são de direito de todos.

Isto posto, a necessidade de celebrar parcerias que possibilitem a estrutura e alcance desses indivíduos ou coletivos são de fulcral importância. Haja vista, que Justiça Itinerante tem capacidade para sanar uma parcela dos problemas decorrentes da desigualdade em que vivenciamos em nosso país, ao passo que os recursos disponíveis para efetivação de todo o trabalho necessário ainda são insuficientes.

Diante deste panorama das iniciativas de justiça itinerante, foi realizada uma parceria da DPU, através dos defensores federais integrantes do projeto itinerante da primeira categoria da DPU-RJ, com a Diocese de Valença/RJ, tendo em vista o impulsionamento do acesso à justiça, no ano de 2019, e pela capilaridade e o acesso aos indivíduos e coletividades por meio das Paroquias inseridas no território diocesano, presente em nove municípios do Centro-Sul Fluminense, anteriormente referenciados.

No que tange a colaboração da Diocese de Valença, foi realizada a parceria com a DPU itinerante, tendo em vista que no mesmo ano, 2019, as Dioceses trabalharam a nível nacional e local com suas respectivas Paróquias e Comunidades o tema "Fraternidade e Políticas Públicas", enaltecendo ainda mais a participação da Justiça Itinerante no território diocesano. Promovendo o contato mais substancial com o público-alvo, encarando a realidade (do órgáo e da população) de forma mais humanizada e responsável (CNBB).

\section{A DIOCESE DE VALENÇA}

A Diocese de Valença, denominada Mitra Diocesana de Valença², foi criada em 1925, pela Bula "Apostólico Ofício", de 27 de março de 1925, do Papa Pio XI. Para pastorear a recém-criada Diocese foi nomeado Dom André Arcoverde de Albuquerque Cavalcanti. Enquanto o novo Bispo náo era ordenado para assumir sua cátedra, foi nomeado como Administrador Apostólico em 21 de agosto de 1925, o Monsenhor Alfredo Bastos, também incansável nos trabalhos preparatórios para que o terreno estivesse pronto para acolher o seu pastor, o seu primeiro Bispo. Criada em março, só em 18 de setembro a Diocese foi canonicamente ereta com a posse de Monsenhor Alfredo Bastos.

2 Para crivo de delimitação, a Diocese de Valença/RJ tem personalidade jurídica própria, denominada Mitra Diocesana de Valença, com seguinte CNPJ 3235643800-01. 
A Diocese de Valença é composta por 26 Paróquias e está presente em 9 Municípios. São eles: Levy Gasparian, Miguel Pereira, Paraíba do Sul, Paty do Alferes, Rio das Flores, Sapucaia, Três Rios, Valença e Vassouras (conforme visto na figura 2). Nestes nove Municípios, milhares de pessoas são assistidas pela Igreja, não só na área da celebração e da formação religiosa, como também nas áreas social e educacional, amparando crianças carentes, deficientes físicos, enfermos, idosos e trabalhadores da cidade e do meio rural. A Diocese promove cursos, seminários, retiros e formaçóes para leigos e religiosos.

Todos os anos, a Conferência Nacional dos Bispos do Brasil (CNBB) lança a Campanha da Fraternidade como um dos principais meios de mobilização nacional, realizada de modo autônomo por cada Diocese que compóe a Igreja Católica Apostólica Romana no Brasil, cujo objetivo é despertar a solidariedade dos seus fiéis e da sociedade em relação a um problema concreto que envolve a sociedade brasileira, buscando caminhos de solução. A cada ano é escolhido um tema, que define a realidade concreta a ser transformada, e um lema, que explicita em que direção se busca a transformação.

Sendo assim, no ano de 2019, o tema elaborado foi "Fraternidade e Políticas Públicas". O seu lema foi inspirado no profeta Isaías: "Serás libertado pelo direito e pela justiça" (Is 1, 27). Por conseguinte, a CF-2019 teve como objetivo geral: "estimular a participação em Políticas Públicas, à luz da Palavra de Deus e da Doutrina Social da Igreja ${ }^{3}$, para fortalecer a cidadania e o bem comum, sinais de fraternidade". Dessa forma, a temática central da CF-2019 encontrava-se com os valores institucionais da DPU, conforme consta no art. 134 da Constituição Federal de 1988, fundamentado na orientação jurídica e na promoção dos direitos humanos e, por isso mesmo, foi incentivada esta cooperação, em vista de tão importante temática trabalhada pela CF e da necessidade de participação cidadã e de direitos de tantos indivíduos despossuídos.

Para a conscientização e informação a Diocese de Valença, em conjunto com suas paróquias, constituiu-se equipes paroquiais para a formação da CF-2019 entres os leigos e leigas do território diocesano. Com o intuito de promover estudos sobre políticas públicas nos nove municípios. $\mathrm{O}$ trabalho das equipes paroquiais da CF buscou destacar, entre os participantes dos eventos paroquiais e diocesanos, que Políticas Públicas não é falar de "politicagem" ou de "eleiçóes", mas significa se referir a um conjunto de açóes a serem implementadas pelos gestores públicos, com o objetivo de promover o bem comum, na perspectiva dos mais pobres da sociedade.

A temática de Políticas Públicas foi trabalhada como ações que são discutidas, aprovadas e programadas para que todo os cidadãos possam ter vida digna. Sendo, concomitantemente, reforçada como a ação do Estado que busca garantir a segurança, a ordem, a dignidade, o bem-estar, por meio de ações baseadas no direito e na justiça. Visto que Políticas Públicas são açóes e programas que são desenvolvidos pelo Estado para garantir e colocar

\footnotetext{
3 É o conjunto de orientaçôes da Igreja Católica Apostólica Romana para os temas sociais. Ela reúne os pronunciamentos do magistério católico sobre tudo que implica a presença do homem na sociedade e no contexto internacional. Trata-se de uma reflexão feita à luz da fé e da tradição eclesial. A função da doutrina social é o anúncio de uma visáo global do homem e da humanidade e a denúncia do pecado de injustiça e de violência que de vários modos atravessa a sociedade.
} 
em prática direitos que são previstos na Constituição Federal de 1988 e em demais leis, dedicadas a garantir o bem-estar da população.

Cabe, assim, às Políticas Públicas, principalmente as assistenciais, o papel de reparação das desigualdades sociais, com a oferta de bens e serviços públicos que rompam com a exclusividade do poder do dinheiro no atendimento das necessidades humanas. Do mesmo modo que a prioridade nas palestras e atendimentos individualizados, por parte da DPU, se pautou nas políticas sociais de acesso universal (ou seja, para todas as pessoas sem nenhum tipo de distinção) nas áreas da educação, saúde e assistência, por exemplo, focando na elevação da qualidade de vida, buscando reduzir as desigualdades no interior e mitigar possíveis assimetrias circunscritas nos municípios.

Sincronicamente, a colaboração entre a DPU itinerante e a Diocese de Valença, bem como sua estrutura e capilaridade nos nove municípios, garantiu aos cidadãos residentes nesses locais - distantes geograficamente das Sedes da Defensoria Pública da União - a assistência jurídica integral, gratuita e de qualidade, uma vez que, mesmo quando cientes da violação de seus direitos, carecem de meios econômicos para se deslocarem até os centros urbanos próximos na busca de Justiça. Ao mesmo tempo que a colaboração e iniciativa prestada difundiu o conhecimento do ordenamento jurídico, dos direitos, bem como da DPU, enquanto instituição que tem por atribuição garanti-los.

\section{DPU ITINERANTE NO CENTRO-SUL FLUMINENSE: METODOLOGIA E ATUAÇÁO}

O Centro-Sul Fluminense foi a principal região nacional produtora de café durante o Império até fins do século XIX. Todavia, após seu período final do ciclo cafeeiro, a região vivenciou décadas das consequências da decadência desta cultura e, hoje, sua economia apoia-se na criação de gado, na olericultura e no turismo. A realidade demonstra que algumas grandes propriedades têm sido transformadas em hotéis-fazenda e sítios de lazer, além disso alguns municípios como Vassouras e Valença também se mostram como polos universitários regionais. Sendo Três Rios seu centro regional, embora suas atividades econômicas já não apresentem o mesmo dinamismo de anos atrás.

De acordo com as estimativas do IBGE para 2014, a população do Sul Fluminense é de 1,2 milhão de habitantes e representa 7,1\% do Estado do Rio de Janeiro. De acordo com os dados da Federação das Indústrias do Estado do Rio de Janeiro - FIRJAN, a riqueza produzida no Sul Fluminense, medida pelo PIB, foi de R $\$ 42,5$ bilhóes em 2012, o que representa $8,4 \%$ do total produzido no Estado. Setorialmente, a maior participação para o produto do Sul Fluminense foi do setor de Serviços e Comércio, que responde por 43,5\% do PIB da região.

Outro dado importante, o índice de Desenvolvimento Humano (IDH) que é uma medida comparativa usada para classificar os países pelo seu grau de "desenvolvimento humano", do mesmo modo que também é usado por organizaçóes locais ou empresas para medir o desenvolvimento de entidades subnacionais como estados e municípios, utilizando como critérios indicadores de educação (alfabetização e taxa de matrícula), longevidade 
(esperança de vida ao nascer) e renda (PIB per capita). Por conseguinte, temos os seguintes índices dos municípios atendidos pelo projeto itinerante: Miguel Pereira, com 0,745; Valença, 0738; Três Rios, 0,725; Vassouras, 0,714; Paraíba do Sul, 0,702; Comendador Levy Gasparian, 0,685; Paty do Alferes, 0,671; Rio das Flores, 0,680; Sapucaia, 0,675.4 Percebemos que os cinco primeiros municípios têm um IDH considerado alto, enquanto os últimos quatro municípios, respectivamente, possuem um IDH médio.

O IDH, cujo valor máximo é de 1,000, nem sempre representa a realidade social das populaçóes locais, desta forma, mesmo nos municípios supra indicados como portadores de índice IDH alto, são encontrados bolsôes de miséria criados pelas políticas econômicas que privilegiam o mercado financeiro em detrimento do elemento humano, como por exemplo no município de Três Rios onde a paróquia de São José Operário acolhe diariamente cerca de cem pessoas para o fornecimento de duas refeiçóes diárias. Migrantes que vieram em busca de um emprego na indústria e que face à recessão hoje sobrevivem em ocupaçóes que geram ganhos eventuais, estando, portanto, juntamente com suas famílias, em verdadeira situação de miséria.

Neste cenário, a atuação do projeto DPU itinerante em parceria com a Diocese de Valença pautou-se na maximização da utilização dos recursos financeiros destinados a execução de projetos itinerantes colocados à disposição para a primeira categoria da DPU-RJ, através do atendimento no maior número de localidades e consequentemente do maior número de pessoas possível, sem que houvesse prejuízo à qualidade do serviço prestado.

Foram definidos os cronogramas de atuação, elaboração dos eventos, publicidade e a definição das atividades que foram desenvolvidas através de dois formatos de atuação. $\mathrm{O}$ primeiro se constituiu por meio da realização de palestras que pudessem esclarecer, em breve síntese, o papel da DPU na assistência jurídica gratuita nacional e internacional; as formas de acesso aos seus serviços; assim como, de forma mais específica os principais temas relativos aos direitos previdenciários e sociais do regime geral da previdência social - INSS.

Em sequência, a outra forma de atuação se deu através de consultas individuais sobre aztemática previdenciária e social, ao final das palestras, com finalidade de sanar as dúvidas dos presentes no que tange à defesa de seus diretos individuais, procedendo-se, quando necessário o encaminhamento dos mesmos, ou de suas demandas, aos órgãos com atribuição para atuação na defesa de seus direitos, incluindo-se neste rol os Ofícios Regionais de Direitos Humanos e Tutela Coletiva da DPU, além é claro da abertura de processos de assistência jurídica - PAJs, para acompanhamento das demandas judiciais pelos Defensores atuantes no projeto itinerante.

Dessa forma o projeto da DPU, como apresentado, em colaboração com a Diocese de Valença e na esteira dos trabalhos realizados com a temática de Políticas Públicas pela CF2019, teve como diferencial o papel de mostrar aos cidadãos que o Estado está atuando efetivamente na busca do atendimento de suas necessidades, através da busca da prestação

\footnotetext{
4 Dados extraídos do Atlas do Desenvolvimento Humano no Brasil 2013. "IDHM Municípios 2010». Programa das Naçóes Unidas para o Desenvolvimento (PNUD). Disponível em: <http://www.br.undp.org/ content/brazil/pt/home/idh0/rankings/idhm-municipios-2010.html>. Acesso em: 25/05/2020.
} 
de serviço público de qualidade - permitindo-lhes o acesso aos benefícios previdenciários e de assistência social.

Os locais de atendimento foram definidos, em parceria entre as instituiçóes, alternando-se os municípios ou localidade próximas, em períodos noturnos e diurnos para facilitação do deslocamento da equipe da DPU.

A DPU disponibilizou um cartaz modelo dos projetos itinerantes onde a Diocese de Valença inseriu os locais, datas e horários de atendimento, os quais foram disponibilizados nas redes sociais, encaminhados aos meios de comunicação, lideranças sociais e religiosas de todas as religióes, orientando-se, ainda, que as paróquias, contatassem as Secretarias de Assistência Social dos municípios para que as mesmas estivessem presentes nos eventos visando a inserção dos assistidos carentes no Cadastro Único para Programas Sociais - CADÚNICO, e orientando sobre os serviços do Serviço Único de Assistência Social- SUAS.

\section{Figura 03: Cartaz de divulgação}

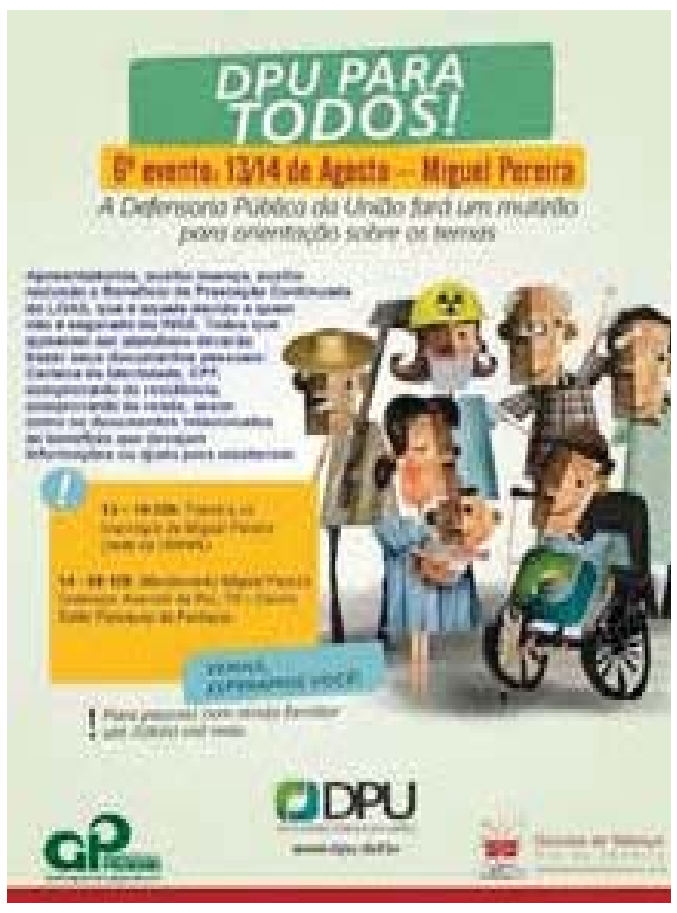

Na parceria com a Diocese de Valença foi acordado que as estruturas físicas para recepção das equipes da DPU deveriam possuir estrutura sanitária, energia elétrica e fácil acesso rodoviário, observando-se, essencialmente, a existência de assentos onde pudessem serem acomodadas as pessoas que comparecessem ao evento, com disponibilização de mesas e cadeiras para que os defensores pudessem atender aos assistidos. 
A logística de atendimento necessitava do apoio dos serviços das secretarias paroquiais, para que obtenção de cópias dos documentos dos cidadãos assistidos no evento e, também, para que estes assistidos pudessem remeter posteriormente os documentos faltantes para a DPU (por meio físico e eletrônico), além de serem os pontos de contato permanente entre os assistidos e a DPU, para futuros esclarecimentos sobre andamento processual, utilizando-se para tanto do e-mail e dos aplicativos virtuais e telefones institucionais, especificamente para aqueles que não possuam meios de acesso digital ou que tenham dificuldades para utilizá-los, tendo em vista que o site da DPU permite o acompanhamento do requerimento e os contatos com os assistidos são feitos através do aplicativo WhatsApp.

Os eventos iniciaram-se com a apresentação institucional da DPU, seguindo-se de breves apresentaçóes sobre os direitos previdenciários e sociais essenciais, os quais a prática demonstrou que devem ser definidos com a participação dos ouvintes, ou seja de acordo com seus interesses, de forma breve, com utilização de linguagem simples e direta, concomitantemente ao registro dos presentes e distribuição de senhas para atendimento individualizado dos que desejassem tirar dúvidas ou apresentarem demandas judiciais.

Os acessos aos serviços individuais de assistência jurídica gratuita foram disponibilizados àqueles que comprovaram serem hipossuficientes economicamente dentro dos padróes de renda estatuídos por normativo nacional da DPU como também pela análise das condiçóes subjetivas dos que alegaram impossibilidade de arcarem com os custos de um processo e contratação de advogado.

As demandas coletivas independem de avaliação da hipossuficiência individualizada, devendo, no entanto, estarem relacionadas com a garantia de acesso aos direitos fundamentais do grupo ou das comunidades tradicionais.

\section{DPU ITINERANTE: A PARTICIPAÇÃO DOS ASSISTIDOS}

Apresentamos, a seguir, a tabela com os números de pessoas que compareceram aos eventos realizados durante o projeto, com indicação individualizada dos locais dos eventos, datas de realização e número de pessoas participantes. 
Tabela 1 - Participaçáo em número de pessoas

\begin{tabular}{|c|c|c|}
\hline DATA & MUNICÍPIO & PARTICIPANTES \\
\hline 04/06/2019 & Valença & 20 \\
\hline 05/06/2019 & Rio das Flores & 31 \\
\hline $25 / 06 / 2019$ & S. Izabel/Valença & 24 \\
\hline $26 / 06 / 2019$ & Quilombo/Valença & 20 \\
\hline 02/07/2019 & Sapucaia & 13 \\
\hline 03/07/2019 & Três Rios & 30 \\
\hline 09/07/2019 & Levy Gasparian & 24 \\
\hline 10/07/2019 & Paraíba do Sul & 12 \\
\hline 06/08/2019 & Paty do Alferes & 14 \\
\hline $07 / 08 / 2019$ & Juparanã -Valença & 24 \\
\hline $14 / 08 / 2019$ & Miguel Pereira & 21 \\
\hline 20/08/2019 & Vassouras & 72 \\
\hline $21 / 08 / 2019$ & Vassouras & 25 \\
\hline $27 / 08 / 2019$ & Vassouras & 10 \\
\hline $28 / 08 / 2019$ & Miguel Pereira & 16 \\
\hline
\end{tabular}

Fonte: tabela produzida pelos autores.

Foram realizados ao todo quinze eventos que contaram com a participação de 356 (trezentos e cinquenta e seis) pessoas, as quais participaram efetivamente como ouvintes das diversas palestras proferidas e foram informadas sobre a possibilidade de receberem atendimento individualizado para esclarecimento de suas dúvidas 5 .

Destacamos que, por sua peculiaridade, o atendimento ao Quilombo de São José da Serra, localizado no distrito rural de Santa Izabel, no município de Valença, com população descendente de escravos que habita este território desde o início do século XIX, que mesmo possuindo acesso rodoviário precário por estrada de terra foi indicado pela Diocese como essencial ao objetivo do projeto, ocasião em que as palestras foram proferidas tanto para os alunos da escola municipal sediada na comunidade como para os demais quilombolas.

Como resultado parcial dos eventos promovidos, foram contabilizados 255 (duzentos e cinquenta e cinco) atendimentos individualizados, baseados em esclarecimentos quanto

5 Destacamos que parte dos presentes também eram lideranças comunitárias. 
aos benefícios previdenciários e sociais; bem como foram realizados encaminhamentos para os órgãos competentes quanto à temática, incluindo-se o Instituto Nacional do Seguro Social - INSS, Secretarias de Assistência Social dos Municípios (CRAS), Defensoria Estadual, entre outros.

Contudo, até o presente momento, ainda não concluiu-se o resultado final do número de processos judiciais propostos, tendo em vista que ainda estáo tramitando alguns procedimentos de assistência - PAJ, que aguardam a devida instrução através de diligências administrativas ou juntada de documentos requeridos aos assistidos, mas podendo-se registrar a propositura de 11 (onze) açóes judiciais, as quais, encontram-se retardadas em seu andamento pela paralisação das atividades presenciais da justiça federal em face da pandemia de COVID -19 .

Entre as açóes judiciais há uma proposta de acordo recebida do INSS para pagamento de valores devidos e implantação do benefício de auxílio doença, e uma sentença favorável com concessão de aposentadoria por tempo de contribuição a uma assistida no município de Rio das Flores, distante cinquenta quilômetros da subseção federal de Barra do Piraí, a qual já iniciou o recebimento de sua aposentadoria através de tutela antecipada e que está aguardando o julgamento do recurso do INSS, junto às Turmas Recursais dos Juizados Especiais Federais no Rio de Janeiro ${ }^{6}$.

\section{CONSIDERAÇÓES FINAIS}

A Diocese de Valença, por seu projeto social em prol da população com maior vulnerabilidade social, pela sua capilaridade nos municípios e seus distritos ${ }^{7}$, de modo extensivo com os trabalhos realizados pelas equipes paroquiais dentro da temática de Políticas Públicas no ano de 2019, colaborou imensamente com a DPU, principalmente orientando a suas lideranças comunitárias a comparecerem ao evento a fim de se capacitarem quanto às temáticas, realizarem sua divulgação e prestarem acolhida àqueles que necessitam de amparo previdenciário e social, possibilitando que pudesse ser efetivado um projeto de prestação de assistência jurídica gratuita que pudesse servir de modelo para que outros idênticos possam ser implantados em todo o Brasil, através das Dioceses.

Constatou-se que cada município tem peculiaridades próprias, por exemplo com relação à grande demanda por obtenção de segunda via de documentos pessoais no município de Três Rios (Paróquia de Sáo José Operário) ${ }^{8}$, assim como, também, no Distrito de Juparanã no município de Valença.

Diante deste quadro, mediante reflexão estratégica, principalmente diante de nossos re-

\footnotetext{
6 Posiçáo de nosso último relatório de acompanhamento em 26 de maio de 2020.

7 Uma vez que a Igreja Católica Apostólica Romana se presente nas localidades onde nem mesmo poder público atinge.

8 Esta demanda se justifica, pois, a Paróquia desenvolve um projeto social com pré-vestibular comunitário, assistência jurídica, psicológica, atendimentos médicos e almoço comunitário para mais de 200 (duzentos) refeições ao dia.
} 
cursos operacionais, não entendeu-se cabível a futura expansão dos partícipes institucionais envolvidos nas açóes deste projeto, pois haveria a necessidade da ampliação da estrutura para a realização dos eventos, o que com certeza atrasaria a celeridade dos atendimentos às pessoas presentes em busca de assistência jurídica gratuita, restando, em situaçôes similares, oficiarmos aos órgãos de assistência pública estadual e municipal, com atribuição legal, para que supram as demandas.

Outrossim, mister esclarecer que estamos diante da implantação de políticas públicas de restrição à delegação de competência previdenciária às Varas Estaduais em todo âmbito nacional, oriundas da Lei $n^{\circ} 13.876$, de 20 de setembro de 2019, que definiu o critério para exercício da competência delegada federal pela Justiça Comum Estadual a partir de $1^{\circ}$ de janeiro de 2020, cuja aplicação no Estado do Rio de Janeiro, por força da Resoluçáo No TRF2-RSP-2019/00091, de 17 de dezembro de 2019, manteve somente as Comarcas Estaduais de Itaocara, Mangaratiba e Paraty competentes para receberem açôes previdenciárias, procedimento este, em nosso entendimento, totalmente equivocado, pois dissociado de medidas que ampliem o acesso da população carente à assistência jurídica gratuita.

Ainda neste cenário, é importante destacar que este projeto foi selecionado a concorrer ao Prêmio Innovare ${ }^{\oplus}$, em sua edição no ano de 2020 . Esta premiação tem como objetivo identificar, divulgar e difundir práticas que contribuam para o aprimoramento da Justiça no Brasil.

Ressalte-se que o atendimento à população é de caráter ecumênico, sempre cabendo tornar pública a informação de que os participantes de todos os credos são bem-vindos ao atendimento, não havendo qualquer tipo de discriminação religiosa e que em momento algum indagar-se-á sobre o credo e a religião de qualquer um dos presentes.

Por fim, concluímos, que a parceria com a Igreja Católica Apostólica Romana, por sua capilaridade representada nas Dioceses a nível nacional com alcance em todos os municípios do Brasil e a cada recanto de seus distritos, representa um modelo de atendimento itinerante de baixo custo e de fácil possibilidade para replicação, pode auxiliar efetivamente à prestação constitucional da assistência jurídica gratuita ao povo brasileiro, porém, de forma alguma vindo a substituir a implantação de sedes da DPU em todos os municípios que possuam sedes das justiças federais como determina o texto da Carta Magna.

\section{REFERÊNCIAS}

ASSIS, Victor Hugo S. Defensoria Pública: histórico, afirmação e novas perspectivas. Revista Defensoria Pública da Uniáo, n.12 p. 1-480 jan/dez, 2019.

CAPPELLETTI, M.; GARTH, B. Acesso à Justiça. Porto Alegre: Fabris, 1988.

CIDH. Convençáo Americana sobre Direitos Humanos. Portal da Convenção Interamericana de Direitos Humanos, 1969. Disponível em: <https://goo.gl/gxEX8K>. Acessado em: 19 de maio 2020.

CNBB. Texto Base da Campanha da Fraternidade de 2019: Fraternidade e Políticas Públicas. Brasília: 2018. 
FIRJAN. Retratos Regionais: perfil econômico regional. Região Sul Fluminense, 2015.

OLIVEIRA, Diego. Democratizaçáo do Direito de Acesso à Justiça: justiça itinerante. Trabalho de Conclusão do Curso de Gestáo de Políticas Públicas da Universidade de Brasília, 2018.

REIS, Elisa Pereira. Pobreza no Brasil: afinal de que se trata. $2^{\text {a }}$. ed., Rio de Janeiro: Editora FGV, 2005.

SOUZA, Celina. Políticas Públicas: uma revisão da literatura. Porto Alegre: Revista Sociologias, pp 20-45, 2006. 